\title{
For the love of learning science: Connecting learning orientation and career productivity in physics and chemistry
}

\author{
Zahra Hazari, ${ }^{1}$ Geoff Potvin, ${ }^{1}$ Robert H. Tai, ${ }^{2}$ and John Almarode ${ }^{2}$ \\ ${ }^{1}$ Department of Engineering \& Science Education, and Department of Mathematical Sciences, Clemson University, Clemson, \\ South Carolina 29634, USA \\ ${ }^{2}$ Curry School of Education, University of Virginia, Charlottesville, Virginia 22904, USA
}

(Received 25 November 2009; published 21 May 2010)

\begin{abstract}
An individual's motivational orientation serves as a drive to action and can influence their career success. This study examines how goal orientation toward the pursuit of a graduate degree in physics and chemistry influences later success outcomes of practicing physicists and chemists. Two main categories of goal orientation are examined in this paper: performance orientation or motivation to demonstrate one's ability or performance to others, and learning orientation or motivation through the desire to learn about a topic. The data were obtained as part of Project Crossover, a mixed-methods study which focused on studying the transition from graduate student to scientist in the physical sciences and included a survey of members of two national professional physical science organizations. Using regression analysis on data from 2353 physicists and chemists, results indicate that physicists and chemists who reported a learning orientation as their motivation for going to graduate school were more productive, in terms of total career primary and/or first-author publications and grant funding, than those reporting a performance orientation. Furthermore, given equal salary, learningoriented individuals produced more primary and/or first-author publications than their nonlearning oriented counterparts.
\end{abstract}

DOI: 10.1103/PhysRevSTPER.6.010107

PACS number(s): 01.40.Fk, 01.40.Ha, 01.85.+f

\section{INTRODUCTION}

The 2007 report Rising Above the Gathering Storm expressed a deep concern over the need to "develop, retain, and recruit the best and brightest students" for "graduate study in areas of national need (p. 3)" [1]. One of the report's recommendations is to focus on attracting and maintaining the "best and brightest" in physical science education through competitive undergraduate scholarships and graduate fellowships for U.S. citizens. However, the report does not provide a sufficient understanding of how to appropriately identify the "best and brightest." By tradition, most award and scholarship programs identify those students with outstanding potential as those who have the highest academic performance outcomes; in particular, grades, standardized test scores (GRE), etc. An individual's interest in or desire for scientific discovery in a field plays a relatively insignificant role. Some assume this type of motivation in graduate school applicants as a given, while others take this desire into serious consideration when gauging potential through more holistic measures such as admissions essays and candidate interviews. In their Science article on indicators of graduate students' success, Kuncel and Hezlett observe that "...student motivation and interest, which are critical for sustained effort though graduate education, must be inferred from various unstandardized measures including letters of recommendation, personal statements, and interviews." [2]. Similarly, Neil deGrasse Tyson emphasized the importance of intrinsic motivation as "[y]ou' ve got to be so deeply in love with your subject that when curve balls are thrown, when hurdles are put in place, you've got the energy to overcome them." [3] Students' motivations to pursue their STEM studies are critically important when studying the drive to action which results in tangible outcomes [4].
With the dawn of the assessment age, there are a plethora of standardized tools, tests, and exams available to teachers and administrators with the purported goal of knowing which students measure up to the rank of "best and brightest" [2,5]. The education system's reliance on these performance measures to rank and reward students has an impact on how students are oriented and what motivates them; in this case, toward the achievement of outcomes such as grades and awards. Students who are oriented in this direction will become excited by the subjects in which they perform well. Thus, their motivation may rely more heavily on their performance in a subject rather than their interests in or conceptual understanding of the subject itself. For example, Carlone [6], in a study of an Active Physics high school classroom, found that many students were more concerned with maintaining their "good student identities" through good grades than with developing connections to physics in a meaningful way. Furthermore, several studies that have empirically supported the social cognitive career theory (SCCT) highlight a worrying trend which indicates that performance is a likely precursor to the development of interest and, ultimately, career choice [7-10]. A critical question that arises from this work is: will the students who are primarily motivated by performance develop into the "best and brightest" scientists?

\section{BACKGROUND}

The role of motivation in student learning as well as in the design and implementation of science instruction has been a topic of research for over three decades [11-17]. As a psychological construct, motivation encompasses "all aspects of activation and intention" and includes both internal stimuli (e.g., interest, values) and external stimuli (e.g., social pressure, material rewards) [4]. Motivation is important to study 
because it is the factor that mediates the drive to action [4]; for science education purposes, students motivated in particular ways may be more easily activated to learn and/or achieve in science classrooms and programs while students motivated in other ways may remain disengaged. To improve the science education system, it is important to understand not only what motivates students to attain desirable outcomes in the classroom but also which motivations lead to desirable outcomes in the future (e.g., becoming a life-long science learner, a successful scientist, etc.) and how to help students develop such motivations. This paper considers the issue by examining what types of earlier motivation influence science outcomes for physical scientists.

There are two major categorizations for motivational stimuli: internal to the self and external to the self. Regardless of which category drives a person to act, Ryan and Deci [4] emphasize the importance of "authentic" motivation; that is, a motivation that is explicitly self-authored or endorsed rather than just an external control. In so defining authentic motivation, it follows that such motivations are intrinsic by nature although they may have begun as extrinsic. For example, Edelson [18] notes, "To create an intrinsic or authentic motivation to learn, the demand must be generated by a natural use of the knowledge. Thus, although a teacher can create a demand for knowledge by creating an exam that requires students to recite a certain body of knowledge, that would not constitute a natural use of the knowledge for the purposes of creating an intrinsic motivation to learn." If the student, however, integrates and internalizes the value and usefulness of the knowledge (in itself or for a self-authored desire, e.g., a personal goal), then they are more likely to become authentically motivated. Although authentic motivations usually stem from internal stimuli, extrinsic motivations can become intrinsic or authentic with the enhancement in feelings of autonomy, competence, and relatedness [4]. Thus, teachers and advisors can promote and facilitate the transfer of extrinsic motivations into more authentic, intrinsic motivations. Finally, authentic motivations have been found to lead to greater interest, excitement, and confidence which can translate into greater performance, persistence, and creativity $[19,20]$. Given the decline in students' STEM interest $[16,21]$, it is important to attempt to understand authentic science motivation and how it can be passed on or stimulated in students to increase the likelihood that they reach the desired educational outcome in more meaningful ways.

One complicating factor, however, is that there are multiple outcomes that are all justifiably valued by science educators (e.g., enjoyment, learning, achievement, etc.) that may be impacted by different motivational stimuli. For this reason, researchers often focus on motivations, actions, and evaluations associated with a specific goal or outcome (e.g., passing tests), usually referred to as goal orientations. The two main goal orientations relevant to educational outcomes are learning orientation (also known as task or mastery orientation) in which the student is motivated to accomplish the goal for mastery and learning of the material, and performance orientation (also known as ability or ego orientation) in which the student is motivated to accomplish the goal to demonstrate their ability or performance to others [22,23].
Learning orientations are often associated with internal stimuli and performance orientations with external stimuli. Prior research in this area has largely focused on examining the impact of these goal orientations on relatively short-term outcomes such as class grades, achievement tests, classroom task performance, usage of higher order learning strategies in classroom activities, and understanding of specific topics [22-26].

Unfortunately, the literature is unclear on the long-term impact of these orientations on productivity and success outcomes, particularly for career scientists. This study examines how learning and performance motivational orientations toward the goal of a graduate career in the physical sciences predict later scientific productivity for physical scientists. While other orientations exist, the current study focuses on these two since they are the most prevalent in the education research literature as well as within the sample used in this paper. To this end, the following research question guided this work:

Do differences in goal orientation related to the choice of pursuing graduate studies in physics and chemistry predict differences in scientific productivity for physical scientists?

In other words, the association between the performance and learning orientations of physical scientists and career productivity (as measured by salary, grant funding, and primary and/or first-author publications) was examined. Understanding the connection between different motivational orientations and future career productivity has implications for the selection and preparation of graduate students in physics and chemistry. This aspect is particularly relevant for the physics education community. In addition, the study further tests a previous finding: that intrinsic motivations ultimately lead to greater performance. Furthermore, this work uniquely contributes to the broader literature by examining the longterm impact of motivational orientation in the sciences and to the physics education literature by employing a motivationrelated framework that has not been widely used.

\section{PHASE I: HYPOTHESIS GENERATION}

The data used in this paper were gathered as a part of Project Crossover, a sequential mixed methodological study designed to examine the transition from graduate student to independent researcher in chemistry and physics. The first phase of the study generated hypotheses through interviews with physical scientists who have experienced (or are currently experiencing) the science career progression from graduate student to independent researcher. The current research question was largely driven by the data and analysis during this phase. The interview component of Project Crossover involved the collection of 125 semistructured interviews with open-ended responses. The interviewees included graduate students, postdoctoral fellows, industrial scientists, and tenured faculty (including two past Nobel prize winners) in physics and chemistry, as well as some individuals who had previously been involved in physics or chemistry but had since left science altogether. The main purpose of 
these interviews was to develop hypotheses linking graduate school experiences with career development among physical scientists. The duration of the interviews ranged from $30 \mathrm{~min}$ to $2.5 \mathrm{~h}$ in length. Audio recordings were transcribed for analysis.

One focus area in the interviews was on the skills and/or qualities that the interviewees considered necessary for success as a physical scientist. A recurring response, prevalent in the interview data, highlighted the need for creativity and passion, above and beyond traditional academic performance abilities. Numerous individuals discussed this quite clearly, for example:

Some people that may not be the best in, say, class work can be very creative in terms of building things or looking at things in different ways. [Faculty member 1, physics]

[W] hen you're a graduate student, ...you can't sustain, you can't work as hard as you need to work and think, you can't read that other paper unless you ...develop some passion for it. [Faculty member 2, physics]

If you love what you do, I'm sure you can be successful. I know people who have sort of bad grades, but they love science. And they've published a lot, and they know just as much [as someone with higher grades]. [Graduate student, chemistry]

These sentiments, along with numerous similar comments from other interviewees, led to a pair of hypotheses: first, that having a joy or passion for carrying out scientific research might be an important indicator of future success; and, second, that such a passion may be more important to individuals' success than their dedication to performing well (in a traditional academic sense). It is these hypotheses that were tested in the second phase of the project. From a certain point of view, these hypotheses are intuitive. The central component of the graduate school experience is a dissertation. This work (and resulting skills) is very different from virtually every other previous formal educational experience: the research is supposed to be original and should be a unique contribution to human knowledge, there are few "correct" answers to be confirmed with other sources, there may be no well-established methodology to utilize, and there are often no clear timelines or end points to the research before undertaking it. Thus, a mismatch between individuals' performance in K-16 education and their performance in science-related work beginning with the doctoral dissertation may potentially exist.

With dissertation-related work in mind, interviewees with experience as graduate advisors were asked if they used any techniques to identify students with the greatest potential. Several interviewees referred to using qualitative measures (e.g., one-on-one discussions with prospective students) as being more valuable than using performance measures (e.g., transcript data) as an indicator. For example, one individual commented:

$[S]$ omebody that's just interested in doing a lot of repetitive experiments in lab, this isn't the place for them. But you can usually tell pretty quickly in an interview ...if somebody has that sort of thinking. [Senior scientist, chemistry]

Unfortunately, even though intrinsic motivations toward science were a highly-valued commodity for physical scientists as an early indicator of potential success, some interviewees noted that efforts toward stimulating students on an affective and/or intrinsic level did not carry sufficient recognition or merit significant personal reward to warrant substantial effort. For this reason, many faculty did not make such efforts. For example:

I don't think the training of future scientists or just the general enjoyment of their students really comes [into it]; it's hard to measure so it's hard to reward. [Postdoctoral fellow, chemistry]

Thus, it was often expected that graduate students should have intrinsic motivations toward science but, at the same time, it was seen as beyond the purview of dissertation advisors to develop such motivations in their students. In fact, advisors that explicitly attempted to motivate students were somewhat anomalous. However, one professor contrasted two motivational approaches to advising from his past experiences, one mainly extrinsic and another that tried to inspire intrinsic motivations:

[My doctoral advisor was] somebody who gets the job done whatever the job is, with stress and with anger and by pushing people around a little bit. And that was the model that I learned ... When I started my post doc it was really exactly the opposite [kind of advising]. It was all sort of... "I'm gonna try to get you so excited about your project ...because this [project] is cool..." So one of the things that I learned was [that] there are different systems. [Faculty member 3, chemistry]

\section{PHASE 2: TESTING HYPOTHESES}

\section{A. Data and data collection}

From the results of the interview phase as well as existing research [27-31], a survey was developed which included 145 questions covering topics ranging from early science motivations, undergraduate and graduate school experiences, and career events after the end of graduate school. Lists of potential participants were obtained from two professional scientific organizations. In 2007, an initial random sample including 13000 members was mailed hard copies of the surveys as well as information to access a passwordprotected online version of the survey. Four reminder mailings followed periodically over the following six months for those who had not responded. Of the 13000 initial surveys mailed, approximately 550 were returned as undeliverable and 3100 responses were determined to be nonapplicable since the recipients did not have the proper background in science. At the conclusion of the collection phase in early 2008, the original sample was determined to include 9343 qualified respondents with correct mailing addresses. From this group, 3220 responded to the survey including physicists, chemists, and other $\mathrm{PhD}$ holders in the physical sci- 
ences. The overall response rate was $34.5 \%$. To assess the representativeness of the final data set, an analysis was carried out to compare respondents' demographic backgrounds (race and/or ethnicity and gender) and employment sectors (universities, federal agencies, nonprofit, for-profit, and other employment not fitting these categories) with the nationally representative sampling found in the National Science Foundations's WebCASPAR database [32]. The Project Crossover sample was found to be similar in proportionate representations across these groupings to the WebCASPAR data.

Although Project Crossover also surveyed currently enrolled graduate students, the current analysis is focused on the aforementioned survey data from $\mathrm{PhD}$ holders since the goal of this work is to understand long-term success outcomes. After accounting for nonresponses to the motivation questions selected for this analysis and accounting for those who had left science entirely, the final sample consisted of 2353 complete surveys including 1462 chemists, 845 physicists, and 46 other physical science PhD holders.

\section{B. Variable construction and validity analysis}

To assess individuals' goal orientation, this analysis is focused on a survey question asking respondents to report their motivations for going to graduate school. From a detailed list of 20 choices, respondents were asked to indicate the two most important factors for going to graduate school. Those selecting "Received good grades in science" or "Awarded scholarship and/or fellowship" were classified as performance-oriented. Those selecting "Enjoyed thinking about science" were classified as learning-oriented. Of the 2353 respondents, 521 were classified as performanceoriented and 949 as learning-oriented, with an overlap of 144 who reported both. There were 1027 respondents having neither performance nor learning orientations; this group is spread across a variety of other motivational orientations including social influences (e.g., teachers, fathers, mothers, or partners and/or spouses) and altruistic aims (i.e., service to humanity). However, performance and learning orientations were the most prevalent orientations.

To evaluate whether the performance and learning orientation measures used in this analysis were assessing individuals' motivations, concurrent criterion-related validity was estimated. That is to say, it was confirmed that the aforementioned measures of goal orientation were strongly correlated with other measures associated to that particular orientation. Since the indicators are binary variables, nonparametric Mann-Whitney U tests were used. The performance orientation measure had a significant, positive correlation with: individuals' high school and college physics and chemistry grades overall $(p<0.001)$, their getting straight A's in chemistry and physics $(p<0.01)$, and the response "Received good grades and/or awards" as the reason for their initial interest in science $(p<0.001)$. As a comparison, learning orientation was also positively correlated with individuals' high school and college physics and chemistry grades overall $(p<0.001)$ but not with their getting straight A's in chemistry and physics. The learning orientation measure also had a significant, positive correlation with: indi- viduals reporting that they developed their own research projects as graduate students $(p<0.01)$, that they explored new research topics for their dissertation $(p<0.05)$, and the response "Enjoyed thinking about science" as the reason for their initial interest in science $(p<0.001)$.

\section{Modeling success with performance and learning orientation}

Next, the associations of the performance and learning orientation measures with three commonly used measures of scientific productivity were investigated. The productivity measures included individuals' current salary, their career total grant funding, and their career total primary and/or firstauthor publications. These measures were constructed from corresponding questions that appeared on the survey asking individuals to indicate their current income, the total amount of grant funding they had been awarded since they earned a doctorate (not including internal funds from their institution and/or company), and the total number of primary and/or first-author publications over their entire career. The sample averages for these measures were, respectively, \$100 300 for salary, \$510 800 for total grant funding, and 21 for total primary and/or first-author publications. The median salary was $\$ 100000$ which closely aligns with the American Institute of Physics (AIP) data reporting a median salary for $\mathrm{PhD}$ holders as \$97 700 in 2006 (mean salary data are not included in the AIP report) [33]. Finally, in measuring the goal orientation of these individuals, note that performance and learning orientation classifications were not mutually exclusive; these orientations were identified in a way that allowed for participants to be categorized as having either, both, or neither orientation. This choice was made since, clearly, individuals can be motivated by multiple factors.

Three multiple regression models containing the learning and performance orientation measures as predictors of each of the productivity outcomes were implemented. Each regression model included variables controlling for gender (male, female), race and/or ethnicity (white, black, asian and/or pacific islander, hispanic, other, multiple responses), field (physics, chemistry), current position (assistant professor, associate professor, full professor, research scientist, postdoctoral researcher, lecturer and/or adjunct, retired and/or emeritus, not currently active in research), type of current institution (public academic, private academic, industry, nonprofit, consultancy, government laboratory, K-12, not currently employed), and years in current position. The results shown in Table I and Fig. 1 indicate that those physical scientists who reported a learning orientation were significantly more successful in terms of grant funding and primary and/or first-author publications than average. There was no significant effect on salary for either orientation. Note that in Model G (Grants), respondents who reported a learning orientation garnered an estimated \$84 600 more in grant funding than their nonlearning-oriented counterparts. In Model P (Primary and/or first-author publications), learning-oriented individuals are estimated to have produced 4.6 more primary and/or first-author publications than their nonlearningoriented counterparts. These results suggest that individuals 
TABLE I. Multiple regression models ${ }^{\mathrm{a}}$ with outcomes of salary, grant funding, and primary and/or first-author publications.

\begin{tabular}{|c|c|c|c|c|c|c|c|c|c|c|c|c|}
\hline & \multicolumn{4}{|c|}{ Model S } & \multicolumn{4}{|c|}{ Model G } & \multicolumn{4}{|c|}{ Model P } \\
\hline & \multicolumn{4}{|c|}{$\begin{array}{c}\text { Salary } \\
\text { (in } \$ 1000)\end{array}$} & \multicolumn{4}{|c|}{$\begin{array}{c}\text { Grants } \\
\text { (in } \$ 1000 \text { ) }\end{array}$} & \multicolumn{4}{|c|}{$\begin{array}{c}\text { Publications } \\
\text { (Primary and/or first) }\end{array}$} \\
\hline & $\mathrm{B}$ & SE & $\beta$ & Sig. ${ }^{b}$ & $\mathrm{~B}$ & $\mathrm{SE}$ & $\beta$ & Sig. ${ }^{b}$ & $\mathrm{~B}$ & SE & $\beta$ & Sig. ${ }^{b}$ \\
\hline Intercept & \multicolumn{4}{|c|}{ Included } & \multicolumn{4}{|c|}{ Included } & \multicolumn{4}{|c|}{ Included } \\
\hline \multicolumn{13}{|l|}{ Controls } \\
\hline \multicolumn{13}{|c|}{ Gender } \\
\hline \multicolumn{13}{|c|}{ Race and/or ethnicity } \\
\hline Field & \multicolumn{4}{|c|}{ Included } & \multicolumn{4}{|c|}{ Included } & \multicolumn{4}{|c|}{ Included } \\
\hline \multicolumn{13}{|c|}{ Current position } \\
\hline \multicolumn{13}{|c|}{ Years in current position } \\
\hline \multicolumn{13}{|c|}{ Orientation } \\
\hline Performance & -0.98 & 2.03 & -0.01 & ns & -31.27 & 36.22 & -0.02 & ns & 0.02 & 1.86 & 0.00 & ns \\
\hline Learning & 0.43 & 1.73 & 0.00 & ns & 84.63 & 30.84 & 0.05 & ** & 4.57 & 1.54 & 0.06 & $* *$ \\
\hline $\mathbf{R}^{2}$ & \multicolumn{4}{|c|}{0.39} & \multicolumn{4}{|c|}{0.28} & \multicolumn{4}{|c|}{0.20} \\
\hline Adjusted $\mathbf{R}^{2}$ & \multicolumn{4}{|c|}{0.39} & \multicolumn{4}{|c|}{0.27} & \multicolumn{4}{|c|}{0.20} \\
\hline $\mathbf{N}$ & \multicolumn{4}{|c|}{2161} & \multicolumn{4}{|c|}{2168} & \multicolumn{4}{|c|}{2166} \\
\hline
\end{tabular}

apolytomous regression analyses were also performed, treating the outcomes as ordinal variables. The resulting models produced similar findings and, thus, multiple regression models are reported here.

$\mathrm{b} * *: p<0.01$, ns: not significant.

motivated by their enjoyment of thinking about science have higher than average levels of scientific productivity. For performance-oriented individuals, no significant effects were found in any of the models. This suggests that individuals motivated by high grades and awards and/or fellowships prior to entering graduate school have levels of scientific productivity that are not significantly different, on average, from researchers who were not motivated by these factors.

These results raised a subsequent question. Learningoriented individuals garner more grant funding (as found in the previous regression models), but might this difference account for the significant, positive effect found for primary and/or first-author publications? It is certainly plausible that research productivity (as measured by primary and/or first-
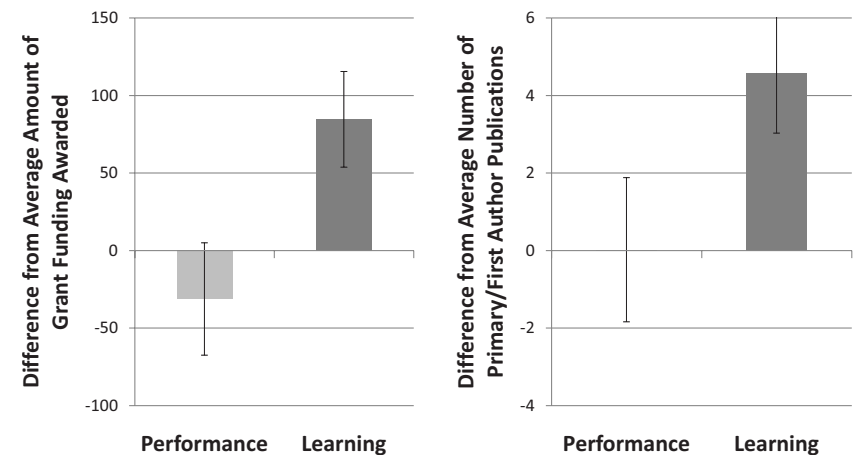

FIG. 1. Effect of learning and performance orientations on grant funding and primary and/or first-author publications for practicing physicists and chemists while controlling for gender, race and/or ethnicity, field, current position, type of institution, and years in current position. Error bars represent \pm 1 standard error. author publications) depends, at least in part, on the level of financial support. Therefore a follow-up question was investigated:

Given equal financial resources from grant funding or salary, are learning-oriented or performance-oriented individuals more productive in terms of primary and/or first-author publications than others?

To some degree, this is a question of "efficiency." If it was found that learning-oriented individuals were more "efficient" in this sense, then this would imply that these individuals do, in fact, produce more scientific publications given the same level of support. On the other hand, if it was found that performance-oriented individuals were more "efficient," then this would imply that those individuals might benefit from being given more resources, despite having less historic success at garnering them.

To answer this second question, grant funding and salary were entered separately into regression models. These models were implemented on the data with primary and/or firstauthor publications as the outcome variable while still controlling for gender, race and/or ethnicity, field, current position, and years in current position. Both were found to be significant predictors at the $p<0.001$ level. Additionally, interactions of performance orientation and learning orientation with grant funding and salary were included in the analysis. The results are shown in Table II.

In Model P-G, grant funding was entered as a predictor of primary and/or first-author publications into the regression model. Neither learning nor performance orientation were found to be significant predictors in Model P-G. It appears that controlling for grant funding subsumes the effects of 
TABLE II. Multiple regression models with outcome of primary and/or first-author publications while accounting for grant funding (Model P-G) and salary (Model P-S). Also considered were interactions of both goal orientations with grant funding and salary.

\begin{tabular}{|c|c|c|c|c|c|c|c|c|}
\hline & \multicolumn{4}{|c|}{ Model P-G } & \multicolumn{4}{|c|}{ Model P-S } \\
\hline & B & SE & $\beta$ & Sig. ${ }^{a}$ & $\mathrm{~B}$ & SE & $\beta$ & Sig. ${ }^{a}$ \\
\hline Intercept & \multicolumn{4}{|c|}{ Included } & \multicolumn{4}{|c|}{ Included } \\
\hline \multicolumn{9}{|l|}{ Controls } \\
\hline \multicolumn{9}{|l|}{ Gender } \\
\hline \multicolumn{9}{|c|}{ Race and/or ethnicity } \\
\hline Field & \multicolumn{4}{|c|}{ Included } & \multicolumn{4}{|c|}{ Included } \\
\hline \multicolumn{9}{|l|}{ Current position } \\
\hline \multicolumn{9}{|c|}{ Years in current position } \\
\hline \multicolumn{9}{|c|}{ Financial resources } \\
\hline Grant funding & 0.013 & 0.001 & 0.28 & $* * *$ & & & & \\
\hline Salary & & & & & 0.15 & 0.02 & 0.20 & $* * *$ \\
\hline \multicolumn{9}{|l|}{ Orientation } \\
\hline Learning & 2.5 & 1.4 & 0.03 & ns & -2.0 & 3.3 & -0.03 & ns \\
\hline Performance & 1.7 & 1.7 & 0.02 & ns & 1.4 & 1.8 & 0.02 & ns \\
\hline \multicolumn{9}{|l|}{ Interactions } \\
\hline Learning ${ }^{*}$ salary & & & & & 0.06 & 0.03 & 0.10 & $*$ \\
\hline $\mathbf{R}^{2}$ & \multicolumn{4}{|c|}{0.25} & \multicolumn{4}{|c|}{0.22} \\
\hline Adjusted $\mathbf{R}^{2}$ & \multicolumn{4}{|c|}{0.24} & \multicolumn{4}{|c|}{0.22} \\
\hline $\mathbf{N}$ & \multicolumn{4}{|c|}{2122} & \multicolumn{4}{|c|}{2112} \\
\hline
\end{tabular}

$\overline{\mathrm{a} *: p<0.05,{ }^{* *}: p<0.01,{ }^{* * *}: p<0.001, \text { ns: not significant. }}$

other predictors with respect to primary and/or first-author publications. This suggests that the impact of receiving significant grant funding on the careers of individual scientists overwhelms any specific effects of either goal orientation. Previously, it was found that individuals who exhibited a learning orientation were associated with higher levels of grant funding. Coupled together, these results suggest a chain of significant associations: holding a learning orientation leads to greater levels of grant funding which leads to greater numbers of primary and/or first-author publications. However, interactions between grant funding and both performance and learning orientations were not found to be significant in this model. Thus, learning-oriented and performance-oriented individuals are equally "efficient" in producing primary and/or first-author publications given the same grant funding, even though learning-oriented individuals are more successful in garnering such funding. This may be explained by the fact that grant funding is not a personal financial resource per se but rather a specific means for carrying out research which allows the hiring of others (e.g., graduate students) to also participate in the research and potentially produce publications. Exploring the issue of efficiency through salary, a personal financial resource for the physical scientist, leads to a further unpacking of the impact of financial resources on the research productivity of learning-oriented and performance-oriented individuals.

In Model P-S, the interaction between learning orientation and salary was found to be significant. This suggests that learning-oriented individuals produce significantly more primary and/or first-author publications than their counterparts with the same salary, on average. The coefficient also suggests that the estimated difference is greater with higher levels of salary. See Fig. 2 for a graphical representation of this

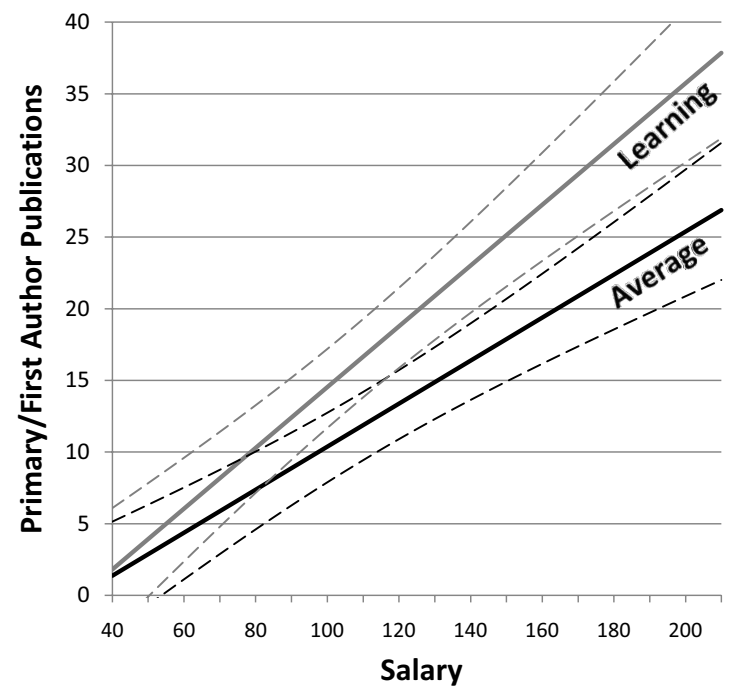

FIG. 2. Regression lines predicting primary and/or first-author publications with increasing salary in thousands while controlling for gender, race and/or ethnicity, field, current position, and years in current position. Dashed lines represent $95 \%$ confidence intervals. 
effect. Coupled with the results of Model S and Model P from Table I, this suggests that learning-oriented individuals are more productive with respect to primary and/or firstauthored publications, on average. Recall in Model $S$ that respondents with a learning orientation were not found to earn higher salaries than average. Model P-S further suggests that, given two prototypical researchers at the same salary, the learning-oriented individual is more productive.

\section{DISCUSSION}

These analyses indicate that those individuals who pursue graduate school because they enjoy thinking about science are particularly productive as scientists (as measured by primary and/or first-author publications and grant funding), while those who pursue graduate school because of good grades and/or awards are no more productive than average. These results are particularly interesting because of the recent focus on standardized assessments and the traditional emphasis on grades as a measure of scientific potential. Kuncel and Hezlett, who synthesized meta-analyses showing connections between standardized test scores and graduate student career outcomes such as degree completion and research productivity, admit that student motivation and interest are critical for a sustained effort and that such motivations cannot be determined from standardized tests [2]. Supporting this claim, the results presented in this paper suggest that an individual's motivation for pursuing science, as expressed by their goal orientation, has implications for their future career as a scientist. Thus, developing constructive orientations should be considered seriously by science educators at all levels; especially since goal orientations are not fixed. The environment of a classroom, school, and even a research group can encourage the adoption of different goal orientations $[22,34]$. It is particularly troubling that the current educational system often promotes the development of a performance orientation so that at later stages students resist meaningful learning and resist adopting a learning orientation in science $[35,36]$. With respect to the result showing a positive relationship between learning orientation and future productivity, it is certainly plausible that those who do a job they love will be more productive than those who are less passionate. Likewise, if students are intrinsically motivated to learn science, it is likely that their understanding of content, academic performance, choice of a science career, and, ultimately, their influence on research may follow [19]. Science educators, who are already focused on developing this motivation within students, now have additional evidence for its importance for those students who pursue science as a career.

Despite the appeal of the finding that learning-oriented individuals are more successful as scientists, for many graduate admissions committees, such factors fade into practical insignificance in comparison to high test scores and grade point averages. The reliance on academic performance often stems from practicality issues and an underlying concern that students be up to the challenge of graduate studies. There is little doubt that high standards for science learning should be maintained as well as efforts to assess that such standards are being met. However, there is a danger in overemphasizing the importance of performance assessments not only because many are not valid measures of genuine learning and/or understanding but also because they can become the primary motivator for individuals. This could lead to an underdevelopment of intrinsic motivations, such as curiosity, which is critical for long-term engagement and success, as has been suggested in this work. Like many issues in education, there is a somewhat delicate balance that needs to be established. For students, research on career choice indicates that performance and achievement are often precursors to students' interest $[8,9]$ rather than vice-versa. Is justice being done to the "best and brightest" in the education system by subtly orienting them toward performance measures rather than toward the excitement of understanding the natural world? Furthermore, are potentially gifted scientists being weeded out through an over-reliance on performance assessments? For students lacking prior academic success, having alternative routes into studying the physical sciences at multiple levels may be one way to help address this potential problem. Offering such alternative paths to careers in scientific research is also likely to enhance the diversity of the scientific workforce.

Project Crossover, the study responsible for collecting the data used in this analysis, was originally conceived in light of the paucity of research on the practice of graduate education in the physical sciences and its impact on scientific productivity. In light of the concerns and recommendations of the National Academies and continuing representation and diversity issues in the physical sciences [1], there is a need to implement reforms that facilitate both the development of more meaningful understanding of students in the physical sciences as well as the development of deeper levels of interest in these fields at all stages including postsecondary education. As educators, it is important to pay attention to the affective and social needs of postsecondary students rather than assuming that students at this stage can maintain their own interest and motivation. Such an assumption may be valid for some students but is certainly not ubiquitous.

The findings in this paper should not be taken as criticism of current scientific researchers of any goal orientation. Rather, this work should serve as motivation to begin to incorporate underemphasized affective domains into educational research outcomes. The results of this work, which is supported by the results of other researchers studying motivation, suggest that individuals who are motivated to do science for intrinsic reasons, such as for the enjoyment gained from generating new knowledge, are ultimately more productive in their research. Furthermore, with worrying trends that indicate an overabundance of performance-oriented students in the education pipeline, it is becoming increasingly apparent that nurturing the personal engagement of students is crucial. More research identifying best practices in this area is necessary. In addition, motivational outcomes should be encouraged by the community as meritorious goals for scientists to foster in their research groups and in their classes. As researchers, it is important to include motivation, identity, and other affective constructs as relevant measures when assessing progress and reform in physics education in addition to more commonly used performance and learning and/or understanding measures. 


\section{ACKNOWLEDGMENTS}

The authors would like to thank the National Science Foundation (NSF) for its support of Project Crossover (NSF
Grant No. 0440002), as well as the scientists who participated in the study and the rest of the Crossover team including X. Fan, Q. Liu, A. Maltese, and V. Wyss.
[1] Rising Above the Gathering Storm: Energizing and Employing America for a Brighter Economic Future, Committee on Prospering in the Global Economy of the 21st Century: An Agenda for American Science and Technology (National Academies Press, Washington, DC, 2007).

[2] N. A. Kuncel and S. A. Hezlett, Sandardized tests predict graduate students' success, Science 315, 1080 (2007).

[3] N. de Grasse Tyson, NOVA, retrieved January 18, 2009 from http://www.pbs.org/wgbh/nova/origins/tyson.html (2004).

[4] R. M. Ryan and E. L. Deci, Self-determination theory and the facilitation of intrinsic motivation, social development, and well-being, Am. Psychol. 55, 68 (2000).

[5] M. J. Bryant, K. A. Hammond, K. M. Bocian, M. F. Rettig, C. A. Miller, and R. A. Cardullo, School performance will fail to meet legislated benchmarks, Science 321, 1781 (2008).

[6] H. B. Carlone, The cultural production of science in reformbased physics: Girls' access, participation, and resistance, J. Res. Sci. Teach. 41, 392 (2004).

[7] N. A. Fouad and P. L. Smith, A test of a social cognitive model for middle school students: Math and science, J. Couns. Psychol. 43, 338 (1996).

[8] N. A. Fouad, P. L. Smith, and K. E. Zao, Across academic domains: Extension of the social-cognitive career model, J. Couns. Psychol. 49, 164 (2002).

[9] R. W. Lent, S. D. Brown, and G. Hackett, Toward a unifying social cognitive theory of career and academic interest., choice, and performance, J. Vocat Behav. 45, 79 (1994).

[10] R. W. Lent, S. D. Brown, J. Schmidt, B. Brenner, H. Lyons, and D. Treistman, Relation of contextual supports and barriers to choice behavior in engineering majors: Test of alternative social cognitive models, J. Couns. Psychol. 50, 458 (2003).

[11] P. C. Blumenfeld and J. L. Meece, Task factors, teacher behavior, and students' involvement and use of learning strategies in science, Elem. Sch. J. 88, 235 (1988).

[12] E. M. Anderman and A. J. Young, Motivation and strategy use in science: Individual differences and classroom effects, J. Res. Sci. Teach. 31, 811 (1994).

[13] M. Druger, Creating a motivational learning environment in large introductory science courses, J. Nat. Resour. Life Sci. Educ. 27, 80 (1998).

[14] A. Cavallo, M. Rozman, J. Blinkenstaff, and N. Walker, Learning, reasoning, motivation, and epistemological beliefs, J. Coll. Sci. Teach. 33, 18 (2003).

[15] S. B. Nolen, Learning environment, motivation, and achievement in high school science, J. Res. Sci. Teach. 40, 347 (2003).

[16] J. Osborne, S. Simon, and S. Collins, Attitudes towards science: A review of the literature and its implications, Int. J. Sci. Educ. 25, 1049 (2003).

[17] S. M. Glynn and T. R. Koballa, Motivation to learn in college science, in Hand. Coll. Sci. Teach, edited by J. Mintzes and W.
Leonard, (NSTA Press, Arlington, VA, 2006), p. 25-32.

[18] D. Edelson, Learning-for-use: A framework for the design of technology-supported inquiry activities, J. Res. Sci. Teach. 38, 355 (2001).

[19] E. Deci and R. Ryan, A motivational approach to self: Integration in personality, in Perspectives on Motivation, Nebraska Symposium on Motivation No. 38, edited by R. Dienstbier (University of Nebraska Press, Lincoln, NE, 1991) pp. 237288.

[20] K. Sheldon, R. Ryan, L. Rawsthorne, and B. Ilardi, Trait self and true self: Cross-role variation in the Big-Five personality traits and its relations with psychological authenticity and subjective well-being, J. Pers. Soc. Psychol. 73, 1380 (1997).

[21] E. Jenkins and N. Nelson, Important but not for me: students' attitudes toward secondary school science in England, Res. Sci. Technol. Educ. 23, 41 (2005).

[22] C. Ames, Classrooms: Goals, structures, and student motivation, J. Educ. Psychol. 84, 261 (1992).

[23] C. A. Wolters, S. L. Yu, and P. R. Pintrich, The relation between goal orientation and students' motivational beliefs and self-regulated learning, Learn. Individ. Differ. 8, 211 (1996).

[24] J. L. Meece, P. C. Blumenfeld, and R. H. Hoyle, Students' goal orientations and cognitive engagement in classroom activities, J. Educ. Psychol. 80, 514 (1988).

[25] P. R. Pintrich, R. W. Marx, and R. A. Boyle, Beyond cold conceptual change: The role of motivational beliefs and classroom contextual factors in the process of conceptual change, Rev. Educ. Res. 63, 167 (1993).

[26] B. S. Bell and S. W. J. Kozlowski, Goal orientation and ability: Interactive effects on self-efficacy, performance, and knowledge, J. Appl. Psychol. 87, 497 (2002).

[27] R. Bucher and J. G. Stelling, Becoming Professional (Sage Publications, Inc., Beverly Hills, CA, 1977).

[28] B. A. Fischer and M. J. Zigmond, Survival skills for graduate school and beyond, New Dir. Higher Educ. 101, 29 (1998).

[29] M. S. Anderson and J. P. Swazey, Reflections on the graduate student experience: An overview, New Dir. Higher Educ. 101, 3 (1998).

[30] C. M. Golde and T. M. Dore, At Cross Purposes: What the experiences of doctoral students reveal about doctoral education (A report prepared for The Pew Charitable Trusts, 2001).

[31] J. G. Gaff, Preparing future faculty and doctoral education, Change 34, 63 (2002).

[32] National Science Foundation, WebCASPAR Database (2009), http://webcaspar.nsf.gov/

[33] R. Chu, Salaries of PhD Physicists and Related Scientists during Spring 2006, Tech. Rep (American Institute of Physics, College Park, MD, 2007).

[34] M. L. Maehr and C. Midgley, Enhancing student motivation: A schoolwide approach, Educat. Psychol. 26, 399 (1991). 
FOR THE LOVE OF LEARNING SCIENCE: CONNECTING...

[35] H. B. Carlone, Innovative science within and against a culture of "achievement", Sci. Educ. 87, 307 (2003).

[36] M. Nieswandt and M.-C. Shanahan, "I just want the credit!" -
PHYS. REV. ST PHYS. EDUC. RES. 6, 010107 (2010)

Perceived instrumentality as the main characteristic of boys' motivation in a grade 11 science course, Res. Sci. Educ. 38, 3 (2008). 